\title{
INFLUENCE OF SULPHURIC ACID CONCENTRATION ONTHE PHYSICO-CHEMICAL PROPERTIES OF MICROFIBRILLATED CELLULOSE FROM OIL PALM EMPTY FRUIT BUNCH FIBRE
}

\section{FATIHA ISMAIL*; NUR ELIYANTI ALI OTHMAN*; NOORSHAMSIANA ABDUL WAHAB* and ASTIMAR ABDUL AZIZ*}

\begin{abstract}
The interest for microfibrillated cellulose (MFC) has been present within the academic sector since the 1980s, but recently this material has become commercially available as it is growing significantly in the industrial sector. Therefore, in this study the oil palm empty fruit bunch fibre (OPEFB-fibre) was selected to be synthesised into MFC. This study focused on the effect of acid concentrations on the isolation of MFC from OPEFB-fibre using the acid hydrolysis method, followed by ultrasonication. The important parameter studied was the concentration of sulphuric acid (10\% to 40\%) while reaction time and temperature were kept constant. The resulting MFC was analysed using Fourier transform infrared spectroscopy (FTIR), thermogravimetric analysis (TGA), X-ray diffractometer (XRD) and scanning electron microscope (SEM). Based on the FTIR results, it was found that the structure of cellulose was retained after undergoing the acid hydrolysis process. The highest thermal stability was obtained when MFC was treated with $20 \%$ sulphuric acid which was determined by using TGA. The XRD method was used to study the structural property of the MFC and the result showed that the MFC produced had 60\% of crystallinity index. The morphological features were identified using SEM. The results showed that the particle size of MFC ranged between 10 $\mu \mathrm{m}$ to $200 \mu \mathrm{m}$. As a result, the parameters used tend to influence the physico-chemical properties of MFC produced and it has the potential to facilitate filler increase in wood-free paper industry.
\end{abstract}

Keywords: empty fruit bunch fibre, microfibrillated cellulose, acid hydrolysis, ultrasonication, physico-chemical.

Received: 26 November 2019; Accepted: 14 February 2020; Published online: 11 September 2020.

\section{INTRODUCTION}

Oil palm empty fruit bunches (OPEFB) is a major agricultural biomass by-product in Malaysia and for each tonne of crude palm oil (CPO) produced will concomitantly give rise to approximately 1.1 $t$ of empty fruit bunch (EFB) as waste residues (Law et al., 2007). OPEFB has been classified as lignocellulosic residues that typically contain 50\%

Malaysian Palm Oil Board,

6 Persiaran Institusi, Bandar Baru Bangi,

43000 Kajang, Selangor, Malaysia.

E-mail: fatiha@mpob.gov.my cellulose, 25\% hemicellulose and 20\% lignin as well as extractive in the cell wall. Besides OPEFB, lignocellulosic residues are also present in the oil palm trunks (OPT), oil palm fronds (OPF), kernel shell, EFB-fibre, pressed fruit fibre (PFF) and palm oil mill effluent (POME). Cellulose is the most abundant renewable natural bio-polymer on earth and is present in a wide variety of living species including plants, animals and some bacteria ( $\mathrm{Li}$ et al., 2009). It is the main structural constituent of plants regaining importance as a renewable chemical resource to replace petroleum-based materials (Beck et al., 2011; Ma et al., 2011). The annual 
production of cellulose is estimated to be over $7.5 \mathrm{x}$ 1010 t (Habibi et al., 2010). For economic feasibility, the cellulose extraction should be integrated with other chemicals extraction such as the hemicellulose (xylan) and the lignin.

In general, the micro- and nano-sized cellulosic materials are produced with different chemical and mechanical methods. In the literature, these materials are termed micro/nanocrystalline cellulose (MCC, NCC), micro/nanofibrillated cellulose (MFC, NFC), cellulose nanowhiskers (CNW), etc. MCC and NCC are needle-shaped, while MFC and NFC are similar to cobweb or spaghetti-shape (Osong et al., 2016). In recent years, the scientific work has focused on two different types of celluloses; MFC and NCC. In addition, MFC is cellulose with a diameter of 0.1-1 $\mu \mathrm{m}$ with a length range of 5-50 $\mu \mathrm{m}$ in which the outer layer of the fibres, which have been stripped away by mechanical shearing, exposes the fibril bundles (Peng et al., 2011). It is a white, fine, odourless crystalline powder and a biodegradable material which can be isolated from pure cellulose through acid hydrolysis method. It can be obtained through homogenisation, microfluiodisation or grinding routes (Peng et al., 2011). MFC is especially well suited for its strength enhancing properties in specialty papers such as filter paper, release liners, labels, decor paper, electrical paper and barrier paper among others. It also can provide strength, stiffness and barrier properties. As a rheology modifier and stabiliser, MFC is ideal for paints, coatings and adhesives (Nathalie et al., 2012).

In order to reduce the cellulose crystallinity, the use of acid hydrolysis has been practiced by previous researchers (El-Sakhawy and Hassan, 2007; Sun et al., 2004). Basically, strong acids are oxidising agents and would dehydrate and redistribute the biopolymers in lignocellulosic materials (Segal et al., 1959). A study by Rozmarin et al. (1977) reveals the effect of acid hydrolysis on the crystallinity of cellulose. The results showed that the crystallinity index decreased rapidly with an increase in acid concentrations. Sulphuric acid has been preferred and widely used in the hydrolysis as compared to others due to its ability to provide a highly stable electrostatic aqueous suspension with the introduction of sulphate groups on the surface of crystallites (Brinchi et al., 2013). From the literature, there is not much chemical treatment approach that was carried out using sulphuric acid hydrolysis at low concentration for environment safety concern (Jonoobi et al., 2012).

The physico-chemical processes are improvement of existing chemical processes, to reduce reaction time and improve the efficiency of the process. In order to enhance the removal of lignin and increase their efficiency, physical parameters such as pressure and temperature are added to the established chemical pre-treatment (Fatiha et al., 2018).
Previous studies show that ultrasonic treatment is significant in lignocellulosic biomass pre-treatment technology to enhance the extractability of main component such as hemicelluloses, cellulose and lignin. Ultrasound increases the cleavage of bonds within lignin as well as the bonds between lignin and hemicellulose. The cleavage reactions are enhanced by radicals produced by ultrasound and the shear forces from ultrasonic mixing improve the degradation of polymer (Bussemaker and Zhang, 2013).

Generally, previous studies focused on the isolation of MCC from oil palm biomass residue (Haafiz et al., 2013) and other materials such as from jute cellulose (Jahan et al., 2011), peel of pear fruits (Habibi et al., 2010), mulberry barks (Li et al., 2009), wheat and cereal straws (Alemdar and Sain, 2008), sugar cane bagasse (Bhattacharya et al., 2008), and soyabean husk (Uesu et al., 2000). This study had successfully isolated MFC from OPEFB instead of MCC using combination of chemical and physical processes. The objective of this study was to determine the effect of acid concentration on the physico-chemical properties of MFC obtained from OPEFB. The physico-chemical properties were characterised using Fourier transform infrared spectroscopy (FTIR) to confirm the basic structure of cellulose in MFC, the thermal stability was carried out using thermogravimetric analysis (TGA), the surface morphology of MFC was monitored using scanning electron microscopy (SEM) as well as the determination of crystallinity index using X-ray diffraction (XRD) analysis. This article reports the pioneering work on the isolation of MFC from OPEFB with different acid concentrations which has a potential to be used as bio-based fillers for environmental-friendly composites.

\section{MATERIALS AND METHODS}

\section{Materials}

Samples of OPEFB shredded fibres were collected from the Palm Oil Mill Technology Centre (POMTEC) located in Labu, Negeri Sembilan, Malaysia. The OPEFB shredded fibres were then transported to MPOB Head Office, Selangor, Malaysia for further processing.

\section{Preparation of Holocellulose and Cellulose}

The OPEFB shredded fibres were initially dried in the oven before use. Dried OPEFB shredded fibres with the average of $0.25 \mathrm{~mm}$ in length were used as a source of cellulose. The dried fibres were first de-lignified according to the American Society for Testing Materials (ASTM), D 1104-56 to produce holocellulose. In this step, about $4.0 \mathrm{~g}$ of the fibres 
were soaked in distilled water and the sample was treated with $2.0 \mathrm{ml}$ of $100 \%$ acetic acid (ChemAR) and $5.0 \mathrm{~g}$ of $99 \%$ sodium chlorite (R\&M, United Kingdom) at $70^{\circ} \mathrm{C}$ for $4 \mathrm{hr}$ to degrade the lignin. The mixture was filtered, and the solid residue, the holocellulose was washed with distilled water.

The next step was to remove the hemicellulose fraction according to ASTM, D 1103-60. About $2.0 \mathrm{~g}$ $\backslash$ of holocellulose was treated with $50 \mathrm{ml}$ of $17.5 \%$ sodium hydroxide solution (99\% Merck, Germany). The insoluble $\alpha$-cellulose was filtered and washed with $8.3 \%$ sodium hydroxide solution. The cleaned $\alpha$-cellulose was used as the starting material for the preparation of microfibrillated cellulose. The detailed characteristic and morphology of $\alpha$-cellulose (lignin content, FTIR, XRD and SEM) were described in previous article (Rosnah et al., 2012).

\section{Preparation of Microfibrillated Cellulose}

The purified cellulose fibres were then subjected to acid hydrolysis reaction at different concentrations of sulphuric acid. The cellulose EFB-fibre (1.0 g) was mixed with $200 \mathrm{ml}$ of $10 \%, 20 \%, 30 \%$ and $40 \%$ sulphuric acid $(\sim 95 \%-98 \%)$ solution. This mixture was then treated by the ultrasonicator at $50^{\circ} \mathrm{C}$ and frequency at $50-60 \mathrm{~Hz}$ for $3 \mathrm{hr}$. After ultrasonication process, the suspension was then washed with distilled water to reach the neutral condition and then filtered to separate the MFC from it. The MFC samples were labelled as MFC1 to MFC4 according to the sulphuric acid percentage $10 \%$ to $40 \%$, respectively. The detailed characteristics and morphology of MFC were characterised using FTIR, SEM, TGA and XRD analysis.

\section{Characterisation of Physico-chemical Properties}

FTIR analysis. Infrared spectra of samples were recorded using a Perkin Elmer-FTIR Spectrum One Spectrometer and transmission was measured in the range of $650-4000 \mathrm{~cm}^{-1}$.

TGA. TGA was performed using Mettler Toledo model to analyse the thermal behaviour of OPEFB and MFC samples. The samples were heated from $30^{\circ} \mathrm{C}$ to $600^{\circ} \mathrm{C}$ with heating rate of $10^{\circ} \mathrm{C} \mathrm{min}{ }^{-1}$ under nitrogen gas atmosphere.

SEM. A Hitachi S2700 SEM was used to evaluate the microscopic features of the samples. A piece of dry sample was put on the SEM sample lens, then the lenses were placed in a vacuum chamber to avoid obstruction and contamination by other particles. The lenses helped to direct electrons towards the sample. The electron imprint was converted into three-dimensional (3D) image. The magnification power used for the samples was 1000X.
XRD. X-ray diffraction (XRD) was carried out to study the crystallinity of the samples. The sample patterns of all the cellulosic and MFC samples were pressed to form pellets and recorded on $X^{\prime}$ Pert X-ray diffractometer (SIEMENs XRD D5000) using Ni-filtered $\mathrm{Cu} \mathrm{K} \alpha$ radiation ( $30 \mathrm{kV}$ and $30 \mathrm{~mA}$ ). The diffraction intensities were measured between Bragg angles $(2 \theta)$ of $5^{\circ}-69^{\circ}$ with $0.04^{\circ} \mathrm{min}^{-1}$ step size. The crystallinity index $\left(C_{I r}\right)$ was calculated by Segal's formula (Segal et al., 1959) using intensity measurement at $22.5^{\circ}$ and $18.5^{\circ}$ (amorphous background) $2 \theta$ :

$$
C_{I r}(\%)=\frac{I_{002}-I_{\mathrm{am}}}{I_{002}} \times 100 \%
$$

where $C_{I r}$ - crystallinity index, whereas $I_{002}$ - maximum intensity (in arbitrary units) of the diffraction from the 002 plane at $2 \theta=22.5^{\circ}$ and $I_{a m}=$ intensity of the background scatter measured at $2 \theta=18.5^{\circ}$.

\section{RESULTS AND DISCUSSION}

\section{Observation of MFC after Acid Hydrolysis Reaction}

Figure 1 demonstrates the appearance of OPEFB fibre and cellulose OPEFB-fibre while Figure 2 shows the hydrolysed MFC fibres at different acid percentage via acid hydrolysis process. For the bleaching process to produce cellulose from OPEFB fibre, the detailed process has been discussed in the preparation of holocellulose and cellulose. The detailed characteristic and morphology of $\alpha$-cellulose (lignin content, FTIR, XRD and SEM) were described in previous article (Rosnah et al., 2012). The MFC fibres in varied acid concentration were hydrolysed for $1 \mathrm{hr}$ reaction. After the acid hydrolysis reaction, a fine fibre structure with pale yellowish colour was observed in MFC1 to MFC3 as depicted in Figures 2a, $2 b$ and $2 c$. Contrary to this observation, the fibres in MFC4 were over hydrolysed and the colour turned to dark brown as shown in Figure $2 d$. This indicated that the fibre structure of $40 \%$ MFC4 treatment (Figure $2 d$ ) was damaged and degraded during the acid hydrolysis. This was detected from the acid treated fibre suspension that had changed to dense dark brown sediment during washing through filtration process. In addition, it was also difficult to leach out the excess acid and neutralise as the acidic solution had incorporated deep into the hydrolysed dense sediment. Hence, the condition for MFC4 disclosed that this treated fibre failed to be further analysed using XRD analysis. Meanwhile, the MFC $10 \%$ to $30 \%$ conditions revealed that the hydrolytic reaction between sulphuric acid and treated fibres had formed a cellulose structure and suitable to be further investigated and discussed. 


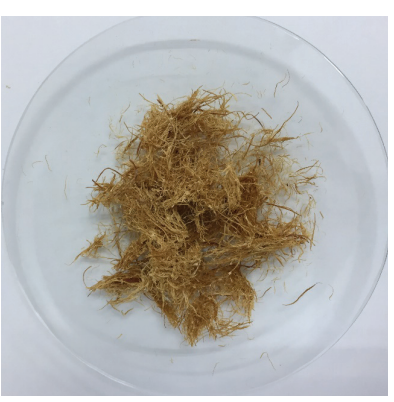

OPEFB fibre

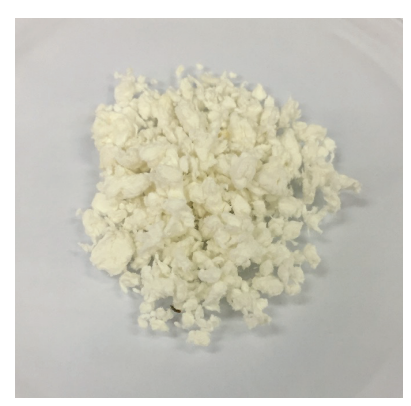

Cellulose OPEFB fibre
Figure 1. The appearance of oil palm empty fruit bunches (OPEFB) fibre and cellulose empty fruit bunches fibre (EFB-fibre).

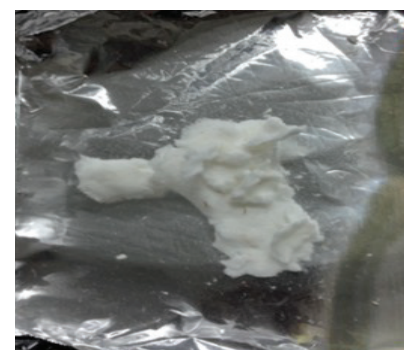

(a) MFC1

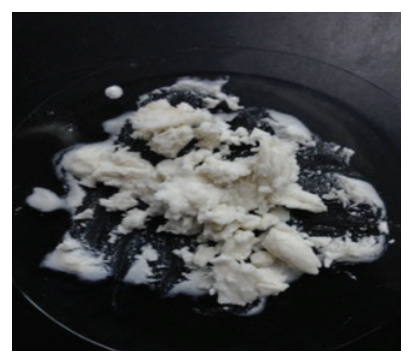

(c) MFC3

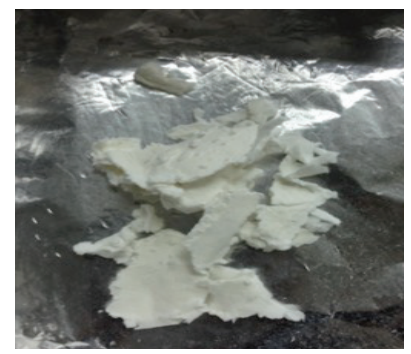

(b) MFC2

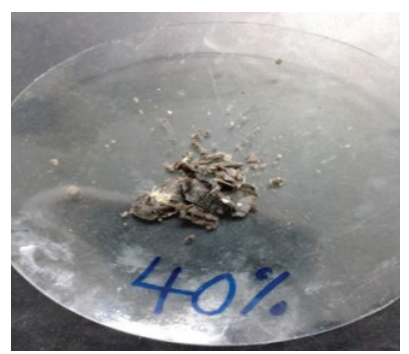

(d) MFC4
Note: $\mathrm{H}_{2} \mathrm{SO}_{4}$ - sulphuric acid.

Figure 2. The microfibrilled cellulose (MFC) with different acid concentration used. (a) MFC1 - $10 \% \mathrm{H}_{2} \mathrm{SO}_{4}$ ( (b) MFC2 - $20 \% \mathrm{H}_{2} \mathrm{SO}_{4}$; (c) MFC3 - 30\% $\mathrm{H}_{2} \mathrm{SO}_{4}$ and (d) MFC4 $-40 \% \mathrm{H}_{2} \mathrm{SO}_{4}$.

\section{FTIR}

FTIR spectra of raw OPEFB-fibre, cellulose OPEFB-fibre and that of MFC1 to MFC4 samples are presented in Figure 3. The peak assignments are depicted in the same figure. Comparing between the raw OPEFB and alkaline treated fibre (cellulose OPEFB), there was no detection of peak intensity at $1732 \mathrm{~cm}^{-1}$ for carbonyl $(\mathrm{C}=\mathrm{O})$ stretching vibrations, suggesting the removal of pectin, hemicellulose or the ester linkage of the carboxylic group of ferulic and p-coumaric acids of lignin or hemicelluloses in the raw fibres. While, the absence of peak intensity at $1265 \mathrm{~cm}^{-1}$ and $1507 \mathrm{~cm}^{-1}$ in the spectra of the alkaline treated fibres indicated the removal of lignin, hemicellulose and waxes (Ireana Yusra et al., 2014). The disappearing of certain peaks in the spectra of other than cellulose OPEFB-fibre indicated that the purification process was successful subject to the removal of lignin, hemicellulose and other impurities. From Figure 3, the FTIR spectra displayed similar pattern and peak position for all MFC samples. The spectral bands located at 3400-3340 $\mathrm{cm}^{-1}$ and 2900 $\mathrm{cm}^{-1}$ were identified in all spectra, thus, represented the $\mathrm{O}-\mathrm{H}$ stretching of intermolecular hydrogen bonds and aliphatic saturated C-H stretching, respectively. The first spectral band observed represents the hydroxyl group which is related to moisture content. This is where the $\mathrm{OH}$ bond is bonded to the structure of cellulose, hemicellulose and lignin. The shoulders which were seen around $1510 \mathrm{~cm}^{-1}$ for the untreated samples demonstrated the aromatic $\mathrm{C}=\mathrm{C}$ bonds in the aromatic rings of lignin. While all peaks and shoulders between $1400-1000 \mathrm{~cm}^{-1}$ for the untreated samples belonged to the typical cellulosic bonds. This indicated that the chemical structure of the cellulosic fragment of MFC have not been affected by the different acid concentrations used in the acid hydrolysis process. Inversely, their morphology and thermal stability could be affected by the high concentration of acid.

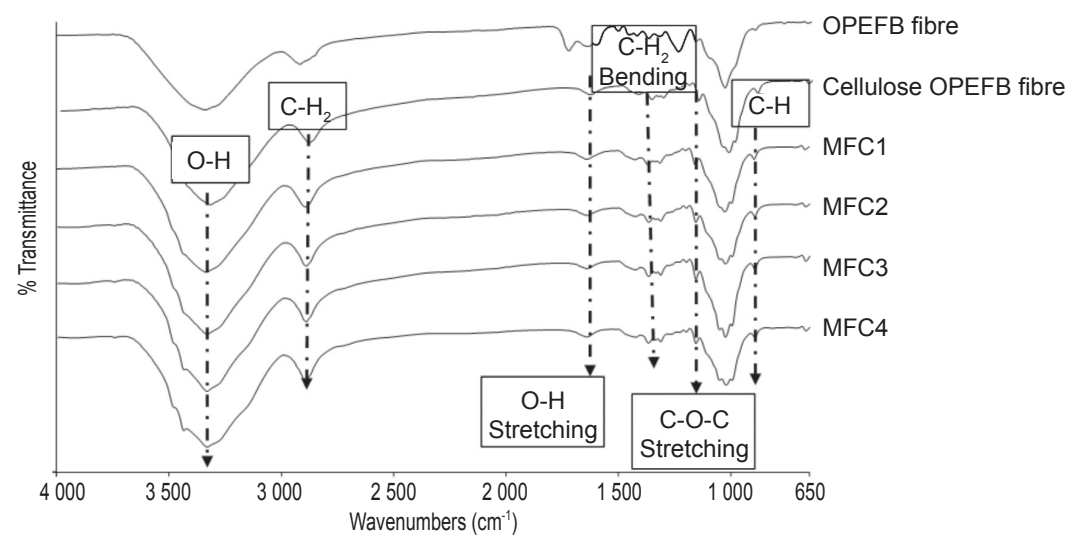

Note: $\mathrm{H}_{2} \mathrm{SO}_{4}$ - sulphuric acid.

Figure 3. The Fourier transformed infrared spectroscopy (FTIR) of oil palm empty fruit bunches (OPEFB), cellulose OPEFB-fibre and microfibrilled cellulose (MFC) with different acid concentrations: MFC1 - 10\% $\mathrm{H}_{2} \mathrm{SO}_{4} ; \mathrm{MFC} 2-20 \% \mathrm{H}_{2} \mathrm{SO}_{4} ; \mathrm{MFC}^{\prime}-30 \% \mathrm{H}_{2} \mathrm{SO}_{4} ; \mathrm{MFC}^{\prime}-40 \% \mathrm{H}_{2} \mathrm{SO}_{4}$. 


\section{Thermal Analysis of Cellulose and MFC}

TGA is a method of thermal analysis in which the mass of a sample is measured over time as the temperature changes. The thermal behaviour and thermal stability of the samples obtained before and after were studied. Figures $4 a$ and $4 b$ show the thermogram of cellulose OPEFB-fibre and MFC 10\% to $40 \%$, respectively. It was observed that all MFC samples displayed single step degradation in the temperature range of $200^{\circ} \mathrm{C}-400^{\circ} \mathrm{C}$ while the weight loss of moisture in the samples was observed at around $100^{\circ} \mathrm{C}$. The thermal stability of the samples was characterised by the temperature at $50 \%\left(\mathrm{~T}_{50}\right)$ and the temperature of the maximum weight loss $\left(\mathrm{T}_{\text {max }}\right)$. It is noted that the MFC2 was stable until a much higher temperature up to $389^{\circ} \mathrm{C}$, as compared to the cellulose OPEFB-fibre because a higher cellulose crystallinity can delay the degradation process and improve the thermal stability (Lima et al., 2004). The $\mathrm{T}_{\max }$ showed that MFC2 exhibited better thermal stability at temperature of $388^{\circ} \mathrm{C}$ as compared to the other MFC. This indicated that the higher decomposition temperature obtained for MFC2 was attributed to the higher crystallinity of cellulose material (Hussin et al., 2016; Osong et al., 2016). From Table 1, it is concluded that the MFC isolated from OPEFB cellulose produced by acid hydrolysis at four different acid concentrations clearly reveals that the acid hydrolysis treatment affects the thermal stability of the MFC.

TABLE 1. DECOMPOSITION TEMPERATURE OF CELLULOSE OIL PALM EMPTY FRUIT BUNCHES FIBRE (EFB-fibre) AND MICROFIBRILLATED CELLULOSE (MFC)

\begin{tabular}{lcc}
\hline \multicolumn{1}{c}{ Samples } & $\mathrm{T}_{50 \%}\left({ }^{\circ} \mathrm{C}\right)$ & $\mathrm{T}_{\max }\left({ }^{\circ} \mathrm{C}\right)$ \\
\hline Cellulose OPEFB-fibre & 318.9 & 357.9 \\
MFC1 & 343.7 & 377.1 \\
MFC2 & 351.7 & 388.8 \\
MFC3 & 305.0 & 364.8 \\
MFC4 & 203.2 & 218.4 \\
\hline
\end{tabular}

Note: $\mathrm{MFC} 1-10 \% \mathrm{H}_{2} \mathrm{SO}_{4} ; \mathrm{MFC} 2-20 \% \mathrm{H}_{2} \mathrm{SO}_{4} ; \mathrm{MFC} 3-30 \% \mathrm{H}_{2} \mathrm{SO}_{4} ;$ MFC4 - 40\% $\mathrm{H}_{2} \mathrm{SO}_{4} ; \mathrm{T}_{50 \%}: 50 \%$ weight loss; $\mathrm{T}_{\max }$ : maximum weight loss.

$\mathrm{H}_{2} \mathrm{SO}_{4}$ - sulphuric acid.

(a)

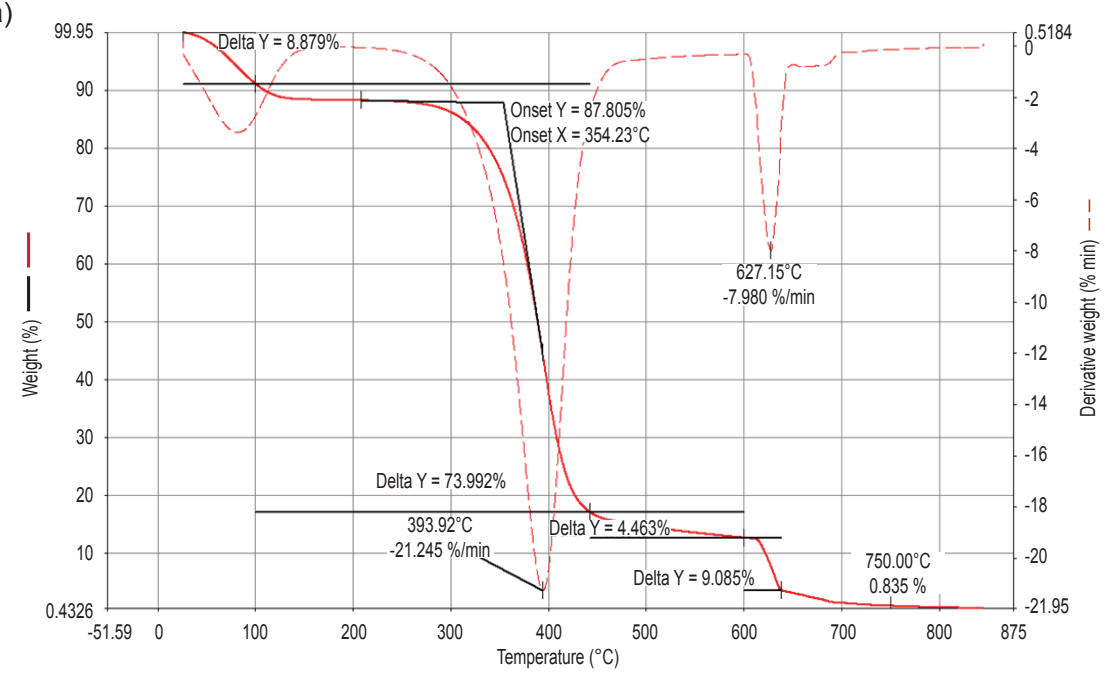

(b)

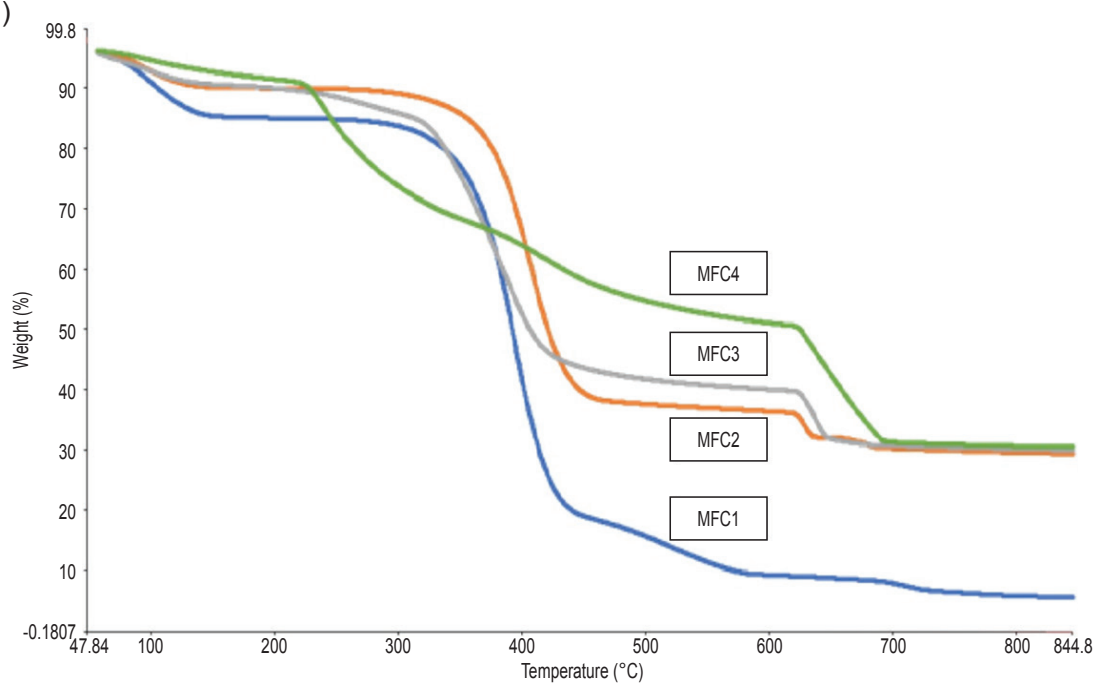

Figure 4. Thermogravimetric profile of (a) cellulose oil palm empty fruit bunches fibre (OPEFB-fibre) and (b) MFC1, MFC2, MFC3 and MFC4. 


\section{SEM Micrographs of Cellulose Before and After Acid Hydrolysis}

The morphological structures of cellulose (before acid hydrolysis) and MFC (after acid hydrolysis) are presented in Figure 5. Based on the figure, it was observed that the morphology of MFC differed after the treatment process. The morphology of MFC revealed that the diameter of MFC decreased along with the shortened length of fibres when the concentration of sulphuric acid increased. The results showed that the acid treatment decreased the widths of the fibres significantly. The width of MFC was decreased from $19 \mu \mathrm{m}$ to $9.4 \mu \mathrm{m}$ at $30 \%$ sulphuric acid concentration (Table 2). This observation is in agreement with the study by Fahma et al. (2010), where it was found that the formation and diameter of the MFC produced greatly depends on the concentration of acid and acid-fibre ratio. Besides that, it can be clearly seen that the external surface of MFC exhibited a smooth surface and irregular structure which was possibly due to the removal of silica, hemicellulose and lignin (Figure $5 b$ ). This showed a good agreement with XRD results where the MFC had higher crystallinity index than cellulose EFBfibre. From Figures $5 a, 5 b$ and $5 c$, the MFC have the average size of 19,11 and $9.4 \mu \mathrm{m}$, respectively, which indicated the disruption of lignocellulosic structure. Through this observation also, the lignin and hemicellulose were removed through bleaching process (Megashah et al., 2018) which caused the defibrillation of fibre bundles into individual microfibrillated cellulose. The raw fibres of OPEFB before treatment is composed of bundles which are bound together by lignin and hemicellulose. The morphology possesses an irregular and rough surface of fibre bundles. Different morphology has been observed on MFC after $40 \%$ sulphuric acid treatment, where the fibres formed rough and dense agglomerated surface morphological structure due to high acid concentration used in the reaction. This similar morphology has been observed during the isolation of MCC by Rosnah et al. (2009).

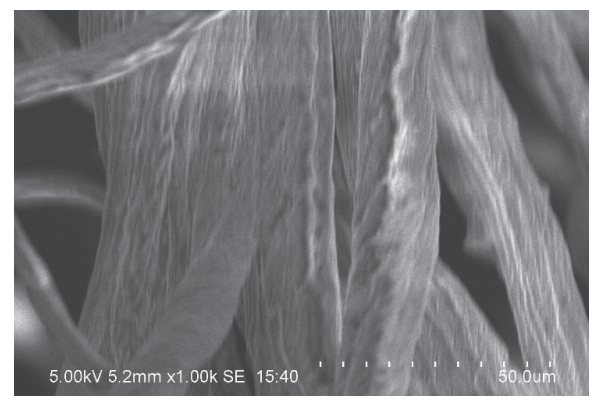

(a) Cellulose oil palm empty fruit bunches fibre (OPEFB-fibre) (before acid hydrolysis).

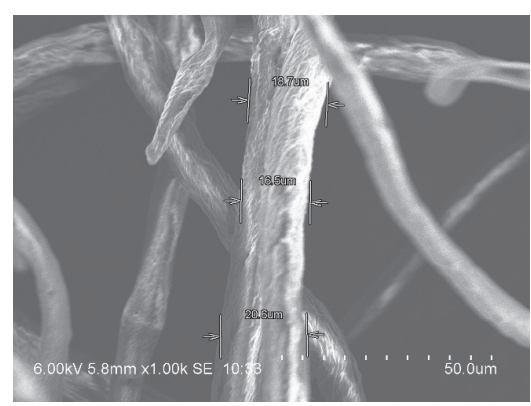

(a) MFC1

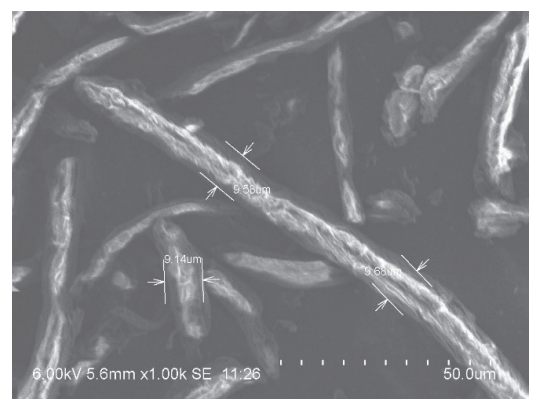

(c) MFC3

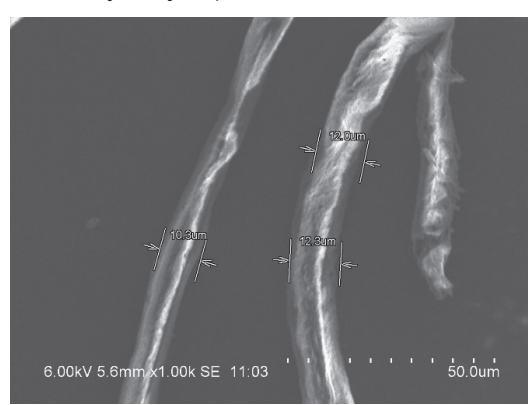

(b) MFC2

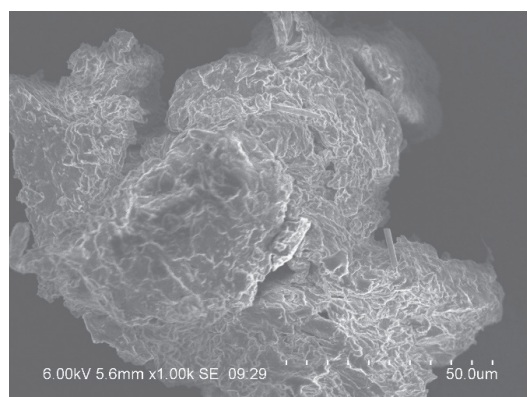

(d) MFC4

Note: $\mathrm{H}_{2} \mathrm{SO}_{4}$ - sulphuric acid.

Figure 5. The scanning electron microscope (SEM) micrograph of cellulose (before acid hydrolysis) and microfibrilled cellulose (MFC) (after acid hydrolysis). MFC1 - 10\% $\mathrm{H}_{2} \mathrm{SO}_{4} ; \mathrm{MFC} 2-20 \% \mathrm{H}_{2} \mathrm{SO}_{4}$ MFC3 - 30\% $\mathrm{H}_{2} \mathrm{SO}_{4} ; \mathrm{MFC} 4-40 \% \mathrm{H}_{2} \mathrm{SO}_{4}$ (1000X magnification). 


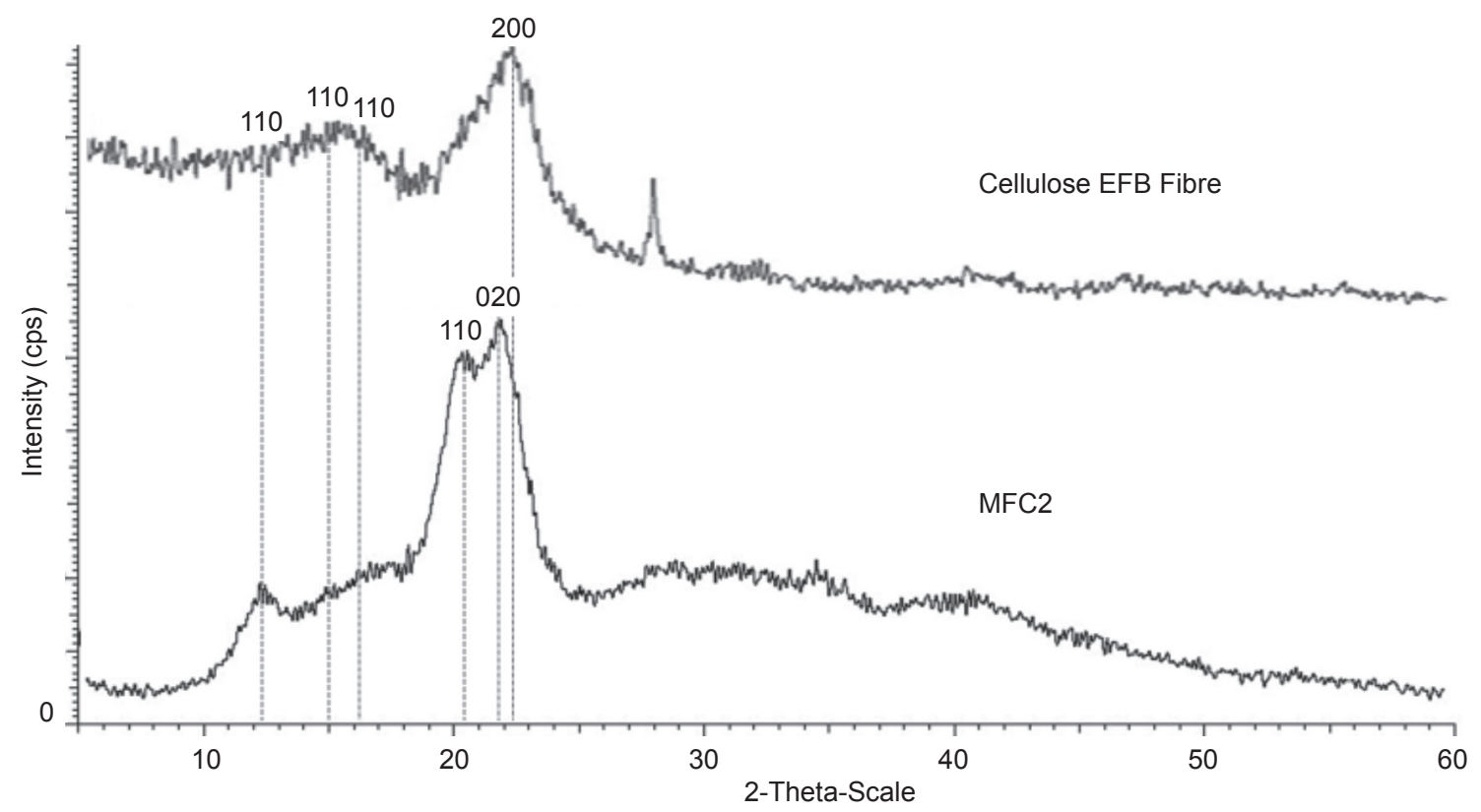

Figure 6. The X-ray diffractograms of cellulose oil palm empty fruit bunch fibre (OPEFB-fibre) and MFC2.

TABLE 2. RANGE OF DIAMETER SIZE OF CELLULOSE EMPTY FRUIT BUNCHES FIBRE (EFB-fibre) AND MICROFIBRILLATED CELLULOSE (MFC)

\begin{tabular}{lc}
\hline Samples & Range diameter size $(\mu \mathrm{m})$ \\
\hline Cellulose OPEFB-fibre & $25-30$ \\
MFC1 & $18-20$ \\
MFC2 & $10-12$ \\
MFC3 & $9.1-9.7$ \\
MFC4 & $>50$ \\
\hline
\end{tabular}

\section{XRD Analysis of Cellulose and MFC}

Generally, the degree of crystallinity of materials is evaluated using the X-ray diffraction method. The degree of crystallinity is the ratio of crystalline areas to amorphous areas in the cellulose. The X-ray diffraction patterns for cellulose OPEFB-fibre and MFC2 are shown in Figure 6. Based on the overall MFC observation, the MFC2 was found suitable and selected for its properties to be further investigated using XRD analysis. This was due to its high decomposition temperature (TGA) and it exhibited a few typical cellulose crystalline peaks in the $2 \theta$ range of $10^{\circ}-40^{\circ}$ (Ma et al., 2011). The crystallinity value was calculated by using Segal's method. The crystallinity values of OPEFB-fibre and MFC2 were $51 \%$ and $60 \%$, respectively (Table 3). As the overall extraction process started from cellulose OPEFBfibre to the isolation of MFC, the crystallinity index kept increasing due to elimination of some hemicellulose and lignin, which existed in the amorphous regions (Chuayjuljit et al., 2010). The alignment of cellulose molecules stands mostly are located at this region. Higher crystallinity is due to more efficient removal of nanocellulosic polysaccharides and dissolution of amorphous zones. The results also confirm that hydrolysis takes place preferentially in the amorphous region as acids dissolve the amorphous regions while crystalline regions are more stable towards chemical attack. However, the interesting observation is that both samples displayed a single peak at theta $22.6^{\circ}$ which represents the cellulose I polymorph structure. Thus, the acid hydrolysis concentration did not affect the cellulose polymorph which was similar to the observation reported by Haafiz et al. (2013) and Rosa et al. (2012).

TABLE 3. THE CRYSTALLINITY INDEX OF CELLULOSE OIL PALM EMPTY FRUIT BUNCHES FIBRE (EFB-fibre) AND MICROFIBRILLATED CELLULOSE 2 (MFC2)

\begin{tabular}{lc}
\hline Name & Crystallinity index (\%) \\
\hline Cellulose EFB-fibre & 51 \\
MFC2 & 60 \\
\hline
\end{tabular}

\section{CONCLUSION}

In this study, MFC was successfully isolated from OPEFB with different acid hydrolysis concentration. For the analysis and description based on appearance of MFC, only MFC fibre hydrolysed at $40 \%$ sulphuric acid was over hydrolysed and turned to dark brown. The results obtained from FTIR analysis showed the chemical structure of the cellulosic fragments were not influenced by different acid concentration treatments. While, SEM analysis showed that all MFC samples have smooth, finer and less aggregated fibril-like structures except for MFC fibre hydrolysed at $40 \%$ sulphuric acid. SEM study demonstrated the smallest diameter of MFC 
was around $9.4 \mu \mathrm{m}$. Based on the TGA results, it can be concluded that MFC treated with $20 \%$ sulphuric acid has good thermal stability as compared to others. Meanwhile the XRD analysis revealed the $C_{I r}$ of MFC2 increased after acid hydrolysis treatment. It is concluded that, acid hydrolysis of fibre using $20 \% \mathrm{H}_{2} \mathrm{SO}_{4}$ for one hour is the optimum condition of acid pre-treatment process based on TGA, SEM and XRD analysis and it has the potential to be used in the production of environmental-friendly filler biocomposites at high temperature range (Jimat et al., 2019; Rozmarin et al., 1977).

\section{ACKNOWLEDGEMENT}

The authors would like to thank the Director-General of MPOB for permission to publish this article.

\section{REFERENCES}

Alemdar, A and Sain, M (2008). Isolation and characterization of nanofibers from agricultural residues - Wheat straw and soy hulls. Bioresource Technology, 99(6): 1664-1671.

Bhattacharya, D; Germinario, L T and Winter, W T (2008). Isolation, preparation and characterization of cellulose microfibers obtained from bagasse. Carbohydrate Polymers, 73(3): 371-377.

Beck, S; Bouchard, J and Berry, R (2011). Controlling the reflection wavelength of iridescent solid films of nanocrystalline cellulose. Biomacromolecules, 12: 167-172.

Brinchi, L; Cotana, F; Fortunati, E and Kenny, J M (2013). Production of nanocrystalline cellulose from lignocellulosic biomass: Technology and applications. Carbohydrate Polymers, 94(1): 154-169.

Bussemaker, M J and Zhang, D (2013). Effect of ultrasound on lignocellulosic biomass as a pretreatment for biorefinery and biofuel applications. Ind. Eng. Chem. Res., 52 (10): 35633580.

Chuayjuljit, S; Su-Uthai, S and Charuchinda, S (2010). Poly(vinyl chloride) film filled with microcrystalline cellulose prepared from cotton fabric waste: Properties and biodegradability study. Waste Management and Research, 28: 109-117.

El-Sakhawy, M and Hassan, M L (2007). Physical and mechanical properties of microcrystalline cellulose prepared from agricultural residues. Carbohydrate Polymers, 67(1): 1-10.
Fahma, F; Iwamoto, S; Hori, N; Iwata, T and Takemura, A (2010). Isolation, preparation, and characterization of nanofibers from oil palm emptyfruit-bunch (OPEFB). Cellulose, 17(5): 977-985.

Fatiha, I; Noorshamsiana, A W; Nur Eliyanti, A O and Astimar, A A (2018). Physico-chemical treatment of oil palm biomass into applicable feedstock. Palm Oil Engineering Bulletin No. 129: 27-37.

Haafiz, M M; Eichhorn, S; Hassan, A and Jawaid, $M$ (2013). Isolation and characterization of microcrystalline cellulose from oil palm biomass residue. Carbohydrate Polymers, 93(2): 628-634.

Habibi, Y; Lucia, L A and Rojas, O A (2010). Cellulose nanocrystals: Chemistry, self-assembly and applications. Chemical Reviews, 110: 3479-3500.

Hussin, M H; Pohan, N A; Garba, Z N; Kassim, M J; Rahim, A A; Brosse, N; Mehdi, Y; Nurul Fazita, M R and Mohamad Haafiz, M K (2016). Physicochemical of microcrystalline cellulose from oil palm fronds as potential methylene blue adsorbents. International J. Biological Macromolecules, 92: 11-19.

Ireana Yusra, A F; Abdul Khalil, H P S; Md Sohrab, H; Astimar, A A; Yalda, D; Rudi, D and Amir, B (2014). Exploration of a chemo-mechanical technique for the isolation of nanofibrillated cellulosic fibre from oil palm empty fruit bunch as a reinforcing agent in composites materials. Polymers, 6: 2611-2624.

Jahan, M S; Saeed, A; He, Z and Ni, Y (2011). Jute as raw material for the preparation of microcrystalline cellulose. Cellulose, 18(2): 451-459.

Jimat, D N; Adi Putra, F; Sulaiman, S; Ahmad Nor, Y; Mohamed Azmin, N F and Syed Putra, S S (2019). Physicochemical characteristics of bionanocomposites, polycaprolactone/starch / cocoa pod husk microfibrillated cellulose. J. Advanced Research in Fluid Mechanics and Thermal Sciences, 55(2): 199-208.

Jonoobi, M; Mathew, A P and Oksman, K (2012). Producing low-cost cellulose nanofiber from sludge as new source of raw materials. Industrial Crops and Products, 40: 232-238.

Law, K N; Daud, W R W and Ghazali, A (2007). Morphological and chemical nature of fibre strands of oil palm empty-fruit-bunch (OPEFB). Bioresources, 2(3): 351-362.

Li, R; Fei, J; Cai, Y; Li, Y; Feng, J and Yao, J (2009). Cellulose whiskers extracted from mulberry: A novel biomass production. Carbohydrate Polymers, 76(1): 94-99. 
Lima, M MD and Borsali, RD (2004). Rodlike cellulose microcrystals: Structure, properties, and applications. Macromolecular Rapid Communications, 25: 771-787.

Ma, H; Zhou, B; Li, H; Li, Y and Ou, S (2011). Green composite films composed of nanocrystalline cellulose and a cellulose matrix regenerated from functionalized ionic liquid solution. Carbohydrate Polymers, 84: 383-389.

Megashah, L N; Ariffin, H; Zakaria, M R and Hassan, M A (2018). Properties of cellulose extract from different types of oil palm biomass. IOP Conference Series: Materials Science and Engineering Vol. 368: 1-11.

Nathalie, L; Isabelle, D; Alain, D and Julien, B (2012). Microfibrillated cellulose - Its barrier properties and applications in cellulosic materials: A review. Carbohydrate Polymers, 90(2): 735-764.

Osong, S H; Norgren, S and Engstrand, P (2016). Processing of wood-based microfibrillar cellulose and nanofibrillated cellulose and applications relating to papermaking: A review. Cellulose, 23: 93-123.

Peng, B L; Dhar, N; Liu, H L and Tam, K C (2011). Chemistry and applications of nanocrystalline cellulose and its derivatives: A nanotechnology perspective. The Canadian J. Chemical Engineering, 89(5): 1191-1206.

Rosa, S M; Rehman, N; De Miranda, M I G; Nachtigall, S M and Bica, C I (2012). Chlorine-free extraction of cellulose from rice husk and whisker isolation. Carbohydrate Polymers, 87(2): 1131-1138.

Rosnah, M S; Astimar, A A; Wan Hasamudin, W H and Ab Gapor, M T (2009). Solid-state characteristics of microcrystalline cellulose from oil palm empty fruit bunch fibre. J. Oil Palm Res. Vol. 21: 613-620.

Rosnah, MS; Astimar, AA; Wan Hasamudin, W H and Ab Gapor, M T (2012). Conversion of lignocellulose from oil palm biomass into water-soluble cellulose ether. J. Oil Palm Res. Vol. 24: 1412-1420.

Rozmarin, G H; Ungureanu, V and Stoleru, A (1977). A study on the supramolecular structure of cellulose carried out by means of acid hydrolysis. Cellulose Chem. and Technology, 11: 523-530.

Segal, L C; Martin, A E and Conrad, C M (1959). An empirical method for estimating the degree of crystallinity of native cellulose using X-ray diffractometer. Textile Res. J., 29: 786-794.

Sun, J X; Sun, X F; Zhao, H and Sun, R C (2004). Isolation and characterization of cellulose from sugarcane bagasse. Polymer Degradation and Stability, 84(2): 331-339.

Uesu, N Y; Pineda, E A G and Hechenleitner, A A W (2000). Microcrystalline cellulose from soybean husk: Effects of solvent treatments on its properties as acetylsalicylic acid carrier. International J. Pharmaceutics, 206(1): 85-96. 